\title{
Rigged or Rigorous? Partnerships for research and evaluation of complex social problems: Lessons from the field of violence against women
}

Cathy Zimmerman ${ }^{\text {a* }}$, Lori Michau ${ }^{\mathrm{b}}$, Mazeda Hossain ${ }^{\mathrm{a}}$, Ligia Kiss ${ }^{\mathrm{a}}$, Rosilyne Borland ${ }^{\mathrm{c}}$ and Charlotte Watts $^{\mathrm{a}}$

a Gender Violence and Health Centre, London School of Hygiene and Tropical Medicine, 15-17 Tavistock Place, London WC1H 9SH. United Kingdom.

${ }^{\mathrm{b}}$ Raising Voices, Uganda

${ }^{\mathrm{c}}$ International Organization for Migration

*Corresponding author.

Email: $\underline{\text { Cathy.Zimmerman@1shtm.ac.uk. }}$

Citation: Zimmerman C, Michau L, Hossain M, Watts C. Rigged or rigorous? Partnerships for research and evaluation of complex social problems: Lessons from the field of violence against women and girls Journal of Public Health Policy.37(Suppl 1):95-109, 2016.

Keywords: Research collaborations; complex social interventions; evaluation, violence against women and girls; impact; research uptake. 


\begin{abstract}
There is growing demand for robust evidence to address complex social phenomena such as violence against women and girls (VAWG). Research partnerships between scientists and nongovernmental or international organisations (NGO/IO) are increasingly popular, but can pose challenges, including concerns about potential conflicts of interest. Drawing on our experience collaborating on VAWG research, we describe challenges and contributions that $\mathrm{NGO} / \mathrm{IO}$ and academic partners can make at different stages of the research process and the effects that collaborations can have on scientific inquiry. Partners may struggle with differing priorities and misunderstandings about roles, limitations and intentions. Benefits of partnerships include a shared vision of study goals, differing and complementary expertise, mutual respect and a history of constructive collaboration. Our experience suggests that when investigating multi-faceted social problems, instead of 'rigging' study results, research collaborations can strengthen scientific rigour and offer the greatest potential for impact in the communities we seek to serve.
\end{abstract}




\section{Background}

With increasingly constrained global investments in health and development and stagnant or declining research budgets, "evidence-informed policy and practice" has become a common funding lexicon. Donor agencies are commissioning scientists and non-governmental and international organizations (NGO/IOs) alike to conduct more rigorous research of complex social phenomena, such as gender-based violence (NGO/IOs may also include community-based organisations, government services working locally or within the community). To inform social and development programs, more funders and agencies are requesting researchers to draw on methods from biomedical studies or clinical trials. While offering great potential for strong findings, these methods can also pose numerous conceptual and methodological dilemmas. ${ }^{1}$ Unlike laboratorybased studies, research into social problems requires not only exploration of the intervention outcomes of interest (e.g., intimate partner violence), but also demands explicit recognition of the context in which events occur. That is, those studying complex social phenomena must investigate "which interventions work for whom under what circumstances". ${ }^{2}$ Attempts to understand multifaceted interactions have led to more research partnerships between academic institutions and local implementing organizations.

Encouragingly, many funders have recognized the benefits of combining academic expertise ("explicit knowledge") with the strong field experience of service and advocacy professionals ("tacit knowledge") — particularly for work on social justice issues such as poverty and inequality. ${ }^{3}$ However, as researchers and implementing agencies join forces, it seems worth considering the challenges and benefits these collaborations can pose for research process. ${ }^{4}$

Among questions that often arise about research partnerships is whether such liaisons might generate findings that are 'rigged' toward outcomes that the implementing or commissioning agency desire, such as arrangements that taint pharmaceutical or tobacco research. Concerns about scientific independence are especially common for methods that clinical trials and epidemiologic studies employ, which, for well-founded reasons, have intentionally maintained a clear separation between evaluation and intervention implementation teams. ${ }^{5}$ Yet, as there is greater demand for more rigorous designs to address social problems, one might ask: Do NGO/IO-academic partnerships violate essential scientific boundaries or researcher autonomy in ways that findings are erroneously swayed (even inadvertently) by organizational ideologies, government relationships, or dominant political and social norms ${ }^{6}$ through, for example, biased research questions or selective use of findings? ${ }^{7}$ 
Once researchers form partnerships, it is not uncommon for philosophical challenges to emerge. For example, differences in partner perspectives may lead to NGO/IO concerns that scientists will misunderstand or distort their program concepts or findings may stigmatize their target population, for instance, by asking irrelevant or misguided research questions or misinterpreting data. It is not unreasonable for implementing groups to ask themselves: Will study findings be presented out of context and perhaps damage important relationships or jeopardize our program or future funding?

Similarly, it is not uncommon for a scientific team to underestimate partners' feelings that others are scrutinizing or judging them, for academic staff to assert a leading versus a collaborative role, or for scientists to undervalue the importance of shared decision-making about methodological options. Suspicions, misunderstandings, and tensions are especially common among groups that have not previously worked together or who have had bad partnership experiences.

We draw on our experience of conducting collaborative research on violence against women and girls (VAWG) to discuss lessons we have learned about the challenges and benefits that partnerships can bring to the research process. Using examples from collaborations between an academic group, the Gender, Violence and Health Centre at the London School of Hygiene and Tropical Medicine (LSHTM), and the implementing organizations, Raising Voices (a local NGO addressing violence against women in Uganda) and the International Organization for Migration, we summarize some of the partnership challenges and suggest ways to strengthen the production of evidence and, ultimately, foster positive impact on policy and programming 
Table 1. Stages of the collaborative research process and input by NGOs/IOs and researchers in research on violence against women (VAWG)

\begin{tabular}{|c|c|c|c|c|}
\hline \multicolumn{2}{|r|}{ Research stage } & \multicolumn{2}{|r|}{ Researcher input } & Implementation example \\
\hline 1. & $\begin{array}{l}\text { Research agenda setting, } \\
\text { methods selection, } \\
\text { impact strategy }\end{array}$ & $\begin{array}{l}\text { - Identify priority questions. } \\
\text { - Consult with stakeholders. } \\
\text { - Identify allies, impact opportunities. }\end{array}$ & $\begin{array}{l}\text { - Identify appropriate research aim(s) and } \\
\text { method(s), measurable outcomes. } \\
\text { - Help identify stakeholders and impact } \\
\text { pathways. }\end{array}$ & $\begin{array}{l}\text { Co-developed plan detailing study questions, } \\
\text { methods, schedule and budget and ongoing } \\
\text { research uptake strategy. }\end{array}$ \\
\hline 2. & $\begin{array}{l}\text { Evidence review, context } \\
\text { assessment, conceptual } \\
\text { framework }\end{array}$ & $\begin{array}{l}\text { - Describe social norms, contextual influences. } \\
\text { - Articulate programming philosophies, change } \\
\text { theories and pathways. }\end{array}$ & $\begin{array}{l}\text { - Review scientific evidence } \\
\text { - Build on theory to develop frameworks. } \\
\text { - Translate programmatic objectives into } \\
\text { measurable variables. }\end{array}$ & $\begin{array}{l}\text { Co-developed conceptual framework with } \\
\text { agreed measurement variables. }\end{array}$ \\
\hline 3. & $\begin{array}{l}\text { Ethics and safety } \\
\text { protocol }\end{array}$ & $\begin{array}{l}\text { - Identify local VAWG risks and safety } \\
\text { mechanisms, trustworthy referral options. } \\
\text { - Input into ethical protocols and monitoring } \\
\text { strategies. }\end{array}$ & $\begin{array}{l}\text { - Formulate traditional and VAWG-specific } \\
\text { ethics protocol. } \\
\text { - Obtain ethical clearance. } \\
\text { - Develop strategies to monitor unintended } \\
\text { outcomes. }\end{array}$ & $\begin{array}{l}\text { Co-drafted ethics and safety protocol, including } \\
\text { referral lists, named referral points, response } \\
\text { and follow-up mechanisms. }\end{array}$ \\
\hline 4. & $\begin{array}{l}\text { Study instruments, } \\
\text { interviewer selection and } \\
\text { training, fieldwork }\end{array}$ & $\begin{array}{l}\text { - } \quad \text { Guide content, phrasing of questions. } \\
\text { - Lead field team recruitment; sensitization on } \\
\text { gender, violence, safe responses. } \\
\text { - Coordinate with community, monitor field } \\
\text { staff interactions and well-being. }\end{array}$ & $\begin{array}{l}\text { - Lead design instrument design } \\
\text { - Select, test scientifically-appropriate tools. } \\
\text { - Train and oversee conduct of research } \\
\text { methods, adherence to protocol(s). }\end{array}$ & $\begin{array}{l}\text { Co-implemented testing of study tools, training } \\
\text { of fieldworkers and supervision of data collection } \\
\text { and security. }\end{array}$ \\
\hline 5. & $\begin{array}{l}\text { Data analysis and } \\
\text { interpretation }\end{array}$ & $\begin{array}{l}\text { - Collaborate to interpret findings to ensure } \\
\text { relevance and avoid stigmatizing. } \\
\text { - Collaborate for priority recommendations, } \\
\text { involvement of stakeholders. }\end{array}$ & $\begin{array}{l}\text { - Conduct analysis, providing preliminary data } \\
\text { analysis. } \\
\text { - Support context-relevant interpretation. } \\
\text { - Ensure recommendations accord with data. }\end{array}$ & $\begin{array}{l}\text { Interpretation meeting to generate joint } \\
\text { interpretation and recommendations. }\end{array}$ \\
\hline 6. & $\begin{array}{l}\text { Achieving research } \\
\text { uptake and impact }\end{array}$ & $\begin{array}{l}\text { - Regularly look for avenues and mechanisms } \\
\text { for dissemination. } \\
\text { - Orient findings for advocacy opportunities. } \\
\text { - Develop innovative communications to share } \\
\text { with communities and stakeholders. }\end{array}$ & $\begin{array}{l}\text { - Develop scientific publication of findings. } \\
\text { - Support communications of results to ensure } \\
\text { technical accuracy and credibility. } \\
\text { - Support dissemination, especially to } \\
\text { academic community. }\end{array}$ & $\begin{array}{l}\text { Joint and separate dissemination activities so } \\
\text { researchers and NGO/IOs can confidently } \\
\text { communicate results and findings are sensitive } \\
\text { to various audiences. }\end{array}$ \\
\hline
\end{tabular}




\section{Researching violence against women and girls}

VAWG is a complex social, development, and human rights problem that is highly prevalent, with one in three women worldwide experiencing violence in her lifetime. ${ }^{8}$ The United Nations defines violence against women as: "any act of gender-based violence that results in, or is likely to result in, physical, sexual or psychological harm or suffering to women, including threats of such acts, coercion or arbitrary deprivation of liberty, whether occurring in public or in private life." ${ }^{\text {VAWG }}$ crosses cultural, age, and economic strata and includes gender-based abuses such as physical and sexual partner and non-partner violence, female genital mutilation, child and forced marriage, sextrafficking, and rape. As calls to address VAWG have risen on the international policy and research agendas, so too have the demands for robust evidence. The complexity of researching VAWG is now well-recognized, as abuses are associated with multiple and interacting interpersonal, cultural, and structural factors, primarily grounded in gender inequality. ${ }^{10}$ This complexity, combined with the serious potential risks associated with investigating gender-based violence, makes it a useful example to discuss how $\mathrm{NGO} / \mathrm{IO}$-academic partnerships affect the research process.

\section{Research methods selection and impact strategy}

Over the past several decades, NGO/IOs and researchers working on violence against women have collectively generated substantial knowledge on gender-based abuses. This evidence has started to help identify determinants, and, importantly, has justified growing policy attention and informed programmatic and research investment. However, the application of more rigorous methodological approaches has sometimes created tensions between research partners. For example, researchers, who may consider methodological decisions as their sole domain, can find it difficult to share methodological decision-making. Yet, when researchers take time to explain and encourage discussion about methodological options, experience suggests that the methods selected are more likely to be feasible in the context, appropriate for the study population, and that budgeting and scheduling will be realistic and findings will be applicable.

Together, partners can determine the evaluation aim and required level of rigour (internal validity). In the case of a newly developed community-based intervention to prevent violence, SASA!, ${ }^{11}$ partners jointly decided when the activities were ready to be subjected to a robust evaluation design, such as a randomized controlled trial (RCT), versus earlier-stage descriptive, developmental research approaches to explore the intervention's feasibility, acceptability, and accessibility. ${ }^{12}$ Once the trial was underway, the evaluation team applied multiple methods (indepth interviews, rapid assessment surveys, quantitative monitoring tools, case studies) to generate diverse data to help support the intervention and interpret the trial results. 
In a positive turn for advocates and researchers alike, the terms "impact" and "research uptake" now appear regularly in research funding calls. ${ }^{13}$ However, because research "impact" is generally considered a target only once a study is completed, strategic plans to achieve impact at various stages throughout a study are rarely developed. Yet, opportunities to influence policies and practices often arise throughout a study. For example, NGO/IOs and the academic team researching health and trafficking in women and girls co-developed the survey questionnaire, which the shelter staff adapted to use as an intake form, thereby improving their detection of clients' health needs. NGO/IOs are often well attuned to local policy priorities and in contact with well-positioned individuals. This can help study teams remain alert to policy windows, for example, to contribute emerging findings in research briefs or for expert consultations.

\section{Review of current evidence, context assessment, and development of conceptual framework}

Research partnerships enhance literature reviews by ensuring that studies go beyond the main subject search and explicitly review contextual factors to develop context-appropriate conceptual frameworks. A conceptual framework is a type of study 'map' that guides the research. For research on violence, teams draw heavily on ecological frameworks that recognize hypothesized or known sources of inequity or exclusion, for example, individual risk factors such as male alcohol misuse, and relationship risk factors, such as early marriage) and social norms that disadvantage women (e.g., gender inequity). ${ }^{14}$ Articulating underlying theories generates joint understanding of research aims, philosophical underpinnings and programmatic thinking. Conceptual frameworks for intervention impact assessments are usually "theories of change." For example, models developed for intervention research in $\mathrm{Uganda}^{15}$ and Cote $\mathrm{d}^{\prime}$ Ivoire $^{16}$ depicted intermediate outcomes, including shifts in power and gender role attitudes, which are hypothesised to be on the pathway to reduced violence. Conversely, conceptual misunderstandings, for example about risk factors, populations under investigation, or NGO/IO's activities, can lead to frustration or even deep mistrust in a team, potentially extending to community wariness of both researchers and NGO/IOs alike.

Conceptual frameworks for research can also become important tools for the field as a whole, particularly when delving into a relatively new subject area, as occurred with a study on the health of trafficked women. ${ }^{17}$ (See Figure 1.) Subsequently, this framework was made available in the WHO factsheet on human trafficking and health for use by the wider policy and practitioner community. ${ }^{18,19}$ 


\section{Influences on health and well-being at various stages of trafficking}

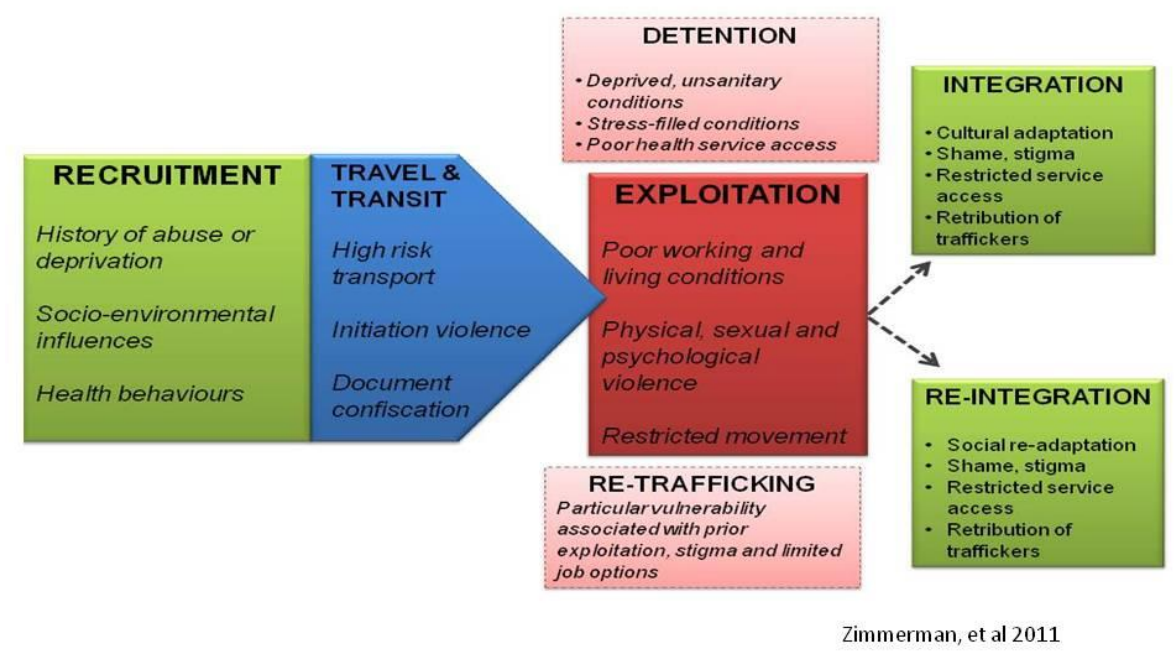

Figure 1. Stages of the trafficking process and influence on health. ${ }^{18}$

\section{Ethics and safety protocols}

A major asset of researcher-NGO/IO collaborations for violence studies is the strength they bring to the safety of study participants and field teams. Because of the special risks posed by studies with vulnerable populations, ethical protocols require an expanded understanding of the principle "do no harm" used in biomedical research to recognise the potential interpersonal dangers of research on sensitive subjects and with marginalised groups. ${ }^{20}$ Even well-intended but poorly considered research can expose women to further violence, risk of retribution from perpetrators, retraumatization or stigma. For example, some forms of contact with individuals who are still in exploitative situations may instigate punishment from traffickers or push the crime further underground, distancing victims from potential assistance.

Ethical protocols for research with especially vulnerable groups, if published widely, can foster better practices by the wider research community, as found in the World Health Organization's ethical and safety recommendations for research on violence against women. ${ }^{21}$

\section{Study instruments, interviewers and field}

Study instruments 
Study instruments form the heart of a study. Specifically, for violence research, questions must be well-formulated and population-sensitive for each particular study group because abuse manifests differently in different settings and local terminology can vary. Researchers may be best placed to identify relevant measurement instruments, while NGO/IOs ensure questions are context-relevant, sensitively phrased, and translated accurately.

\section{Interviewer training and fieldwork}

Studies and field experience in violence research demonstrate that collaborative work to ensure fieldworker selection, sensitization, and training helps ensure participant and researcher safety and can also affect findings. A study on partner violence in Nicaragua using standard household survey methodology was repeated by NGO/IO-research partners who identified much higher violence levels (28\% versus 52\%-69\%) after applying a more detailed ethical protocol and investing more time in researcher training. ${ }^{22}$ Fieldworker training by both NGO/IOs and researchers can ensure teams adhere to study protocols, respond appropriately to distress, and make referrals to assistance when needed.

\section{Data analysis and interpretation}

Scientists are responsible for data analysis. However, well-interpreted findings require joint input, and collaborative interpretation remains among the most commonly lost opportunities and can lead to misleading results or weak recommendations. ${ }^{23}$ Collective consideration of data can help clarify context-specific meaning, identify policy relevance, prevent selective use of data, and ensure findings are relevant and comprehensible to their target audiences. ${ }^{24} \mathrm{NGO} / \mathrm{IOs}$, in particular, warn when data do not accord with their on-the-ground experience. For example, when piloting established tools to measure gender attitudes in Uganda, the team found a questionably high rate of positive gender-sensitive attitudes among men, which was ultimately attributed to social desirability bias. Data interpretation may also involve additional stakeholders (beneficiaries, local leaders, donors, government representatives) to strengthen recommendations and identify avenues for impact (policy champions).

Table 2. Examples of NGO-researcher collaborations on violence and impact.

\begin{tabular}{|c|c|c|c|}
\hline $\begin{array}{c}\text { Target population, } \\
\text { (study countries) }\end{array}$ & Study design and aim & Example of policy influence & $\begin{array}{c}\text { Example of programme } \\
\text { influence }\end{array}$ \\
\hline
\end{tabular}




\begin{tabular}{|l|l|l|l|}
\hline $\begin{array}{l}\text { SASA!a Women and } \\
\text { men, leaders and } \\
\text { service providers in } \\
\text { communities in } \\
\text { Kampala, Uganda. }\end{array}$ & $\begin{array}{l}\text { Randomized Controlled } \\
\text { Trial to evaluate } \\
\text { effectiveness of SASA! } \\
\text { approach to reduce } \\
\text { intimate partner violence } \\
\text { and HIV risk behaviors. }\end{array}$ & $\begin{array}{l}\text { Advocacy with the Ministry of } \\
\text { Gender, Labor and Social } \\
\text { Development to include } \\
\text { prevention in a National Plan of } \\
\text { Action on VAWG Prevention in } \\
\text { Uganda. }\end{array}$ & $\begin{array}{l}\text { Used evidence for advocacy in } \\
\text { with the Government of Uganda } \\
\text { to pilot SASA! implementation in } \\
\text { Busoga region through local } \\
\text { government. }\end{array}$ \\
\hline $\begin{array}{l}\text { Stolen Smiles } \\
\text { Survivors of sex } \\
\text { trafficking; (UK, } \\
\begin{array}{l}\text { Belgium, Moldova, } \\
\text { Ukraine, Italy, Czech } \\
\text { Republic, Bulgaria). }\end{array}\end{array}$ & $\begin{array}{l}\text { Prospective survey of } \\
\text { women in post-trafficking } \\
\text { services to identify health } \\
\text { needs. }\end{array}$ & $\begin{array}{l}\text { Data on mental health use to } \\
\text { advocate for 90-day recovery } \\
\text { period for victims of trafficking in } \\
\text { UK legislation; advocacy in EU } \\
\text { for recognition of health impacts } \\
\text { of trafficking. }\end{array}$ & $\begin{array}{l}\text { Conceptual model used as } \\
\text { WHO framework for health and } \\
\text { trafficking; study tools } \\
\text { incorporated into service intake } \\
\text { forms for violence, mental } \\
\text { health. }\end{array}$ \\
\hline $\begin{array}{l}\text { Men's Discussion } \\
\text { Groupsc Men and } \\
\text { women in conflict- } \\
\text { affected settings. (6 } \\
\text { rural districts in Cote } \\
\text { d'Ivoire (CI)). }\end{array}$ & $\begin{array}{l}\text { Cluster randomized } \\
\text { controlled trial to assess } \\
\text { the impact of working } \\
\text { with men to reduce } \\
\text { intimate partner violence } \\
\text { among conflict-affected } \\
\text { populations. }\end{array}$ & $\begin{array}{l}\text { Advocacy in Cl and } \\
\text { internationally to expand } \\
\text { understanding and focus on } \\
\text { violence in conflict settings and to } \\
\text { promote work with men. }\end{array}$ & $\begin{array}{l}\text { Program strengthened from } \\
\text { findings and replicated in other } \\
\text { sub-Saharan conflict-affected } \\
\text { countries. International training } \\
\text { of trainers for other } \\
\text { organizations. }\end{array}$ \\
\hline
\end{tabular}

a(Abramsky et al., 2014)

b(C Zimmerman, Hossain, Yun, Roche, et al., 2006; C Zimmerman, Hossain, Yun, Watts, et al., 2006)

c (Hossain et al., 2014)

\section{Research uptake and impact}

A tremendous amount of important evidence often slips silently away into the pages of academic journals. Yet, this evidence-disappearing act can become the exception not the rule if donors make clear budget provision for research uptake activities, and if research teams are dedicated to continuous planning to achieve wide-ranging impact.

Although assurances of feedback to local communities are commonly voiced at the outset of a study, efforts often diminish towards the end when time and resources run thin. NGO/IOs are particularly wellplaced and have substantial motivation to fulfil their promises and promote the rights of their constituency. In a recent call to action to address violence against

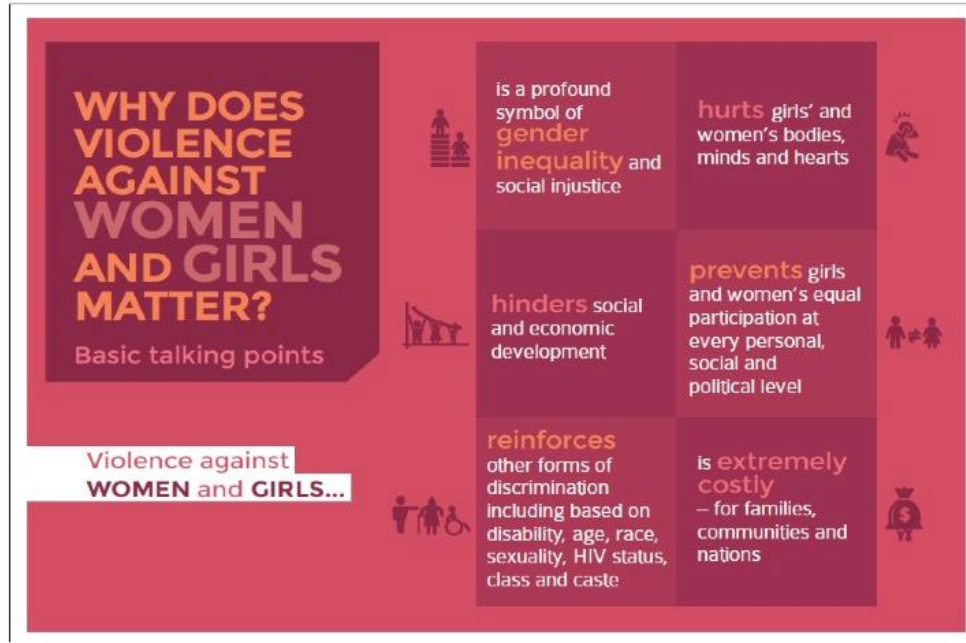

Figure 2. Example of popularization of academic research (by Raising Voices, Uganda). ${ }^{25}$ 
women, co-written by scientists and non-scientists, the Raising Voices team translated the ideas into a popularized version that could be easily disseminated to a wider audience. ${ }^{25}$ (See Figure 2.)

\section{Partnership constraints and strategies}

Even in the most well-formed collaborations, tensions can arise. It is not uncommon for NGO/IOs to perceive that their research colleagues undervalue their knowledge and skills. Indeed, sometimes researchers may not sufficiently acknowledge the crucial expertise of their NGO/IO partnersmistakenly viewing them solely as conduits to access study populations. (See Figure 3.)

Time pressures in studies can be pernicious. Conflicting time commitments are especially problematic when journal publication dates prolong the release of findings to the community. For local organizations, delayed dissemination can mean they risk losing the confidence of their constituency, seeming to renege on their promises. Study teams can plan for the possibility of delay by finding ways to release some findings, in 'closed-door' meetings or stakeholder consultations. Once journals publish peer-reviewed papers, this scientific evidence often operates as an influential advocacy tool.

As findings become public, it is important for researchers to help NGO/IOs to speak competently and confidently about the technical aspects of the study, and for NGO/IOs to help researchers understand the local politics and policy and make relevant and convincing recommendations.

Finally, it would be naive to discuss partnership challenges without mentioning funding and budgeting. There can be little doubt that money can be a source of significant tension. Especially in new partnerships, feelings of enthusiasm for the research are often accompanied by caution, even suspicion, about how the finances and workload will be structured. NGO/IOs must also weigh priorities: Is it better to spend funds on activities to meet needs or invest in knowledge- and evidence-building to inform future programming or policy? While funding allocation and budgeting is beyond the scope of this paper, it is worth noting that transparency with budgets and regular communications about expenditures are essential to a trusting working relationship. A great deal of good will can be lost through poor communication about money. 


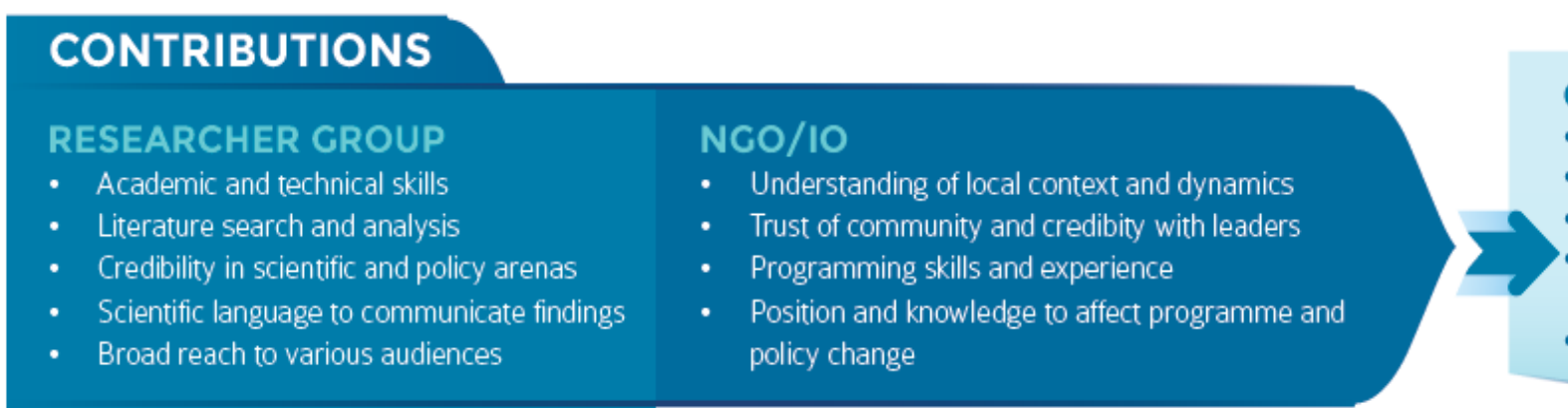

\section{CONTRIBUTIONS}

RESEARCHER GROUP

- Academic and technical skills

- Broad reach to various audiences

Position and knowledge to affect programme and policy change
Committed to

- Gender-based analyses of VAWG

- Doing no harm and putting women first

Scientific rigour

Recognition of the complexity of social phenomena

Using results for change

Resolved through

\section{RIGOROUS, IMPACT-ORIENTED VAWG RESEARCH}

- Shared vision of goals and what is possible

- Open communications

- Demonstration of mutual respect

- Valued and respectful use of partner knowlede and skills

- Clarity of roles, needs, expectations, responsibilities

- Well-articulated and regularly up-dated research and dissemination schedule

\section{RESEARCHER GROUP}

- Adjustment to local or programmatic context and culture

- Being the 'outsider'

- Learning time of programmatic assumptions

- Making methodological compromises

- Scrutiny of scientific autonomy or academic independence

- Accomodating pace of programming and evidence needs

\section{CONSTRAINTS}

$\mathrm{NGO} / \mathrm{IO}$

- Feeling judged or scrutinized

- Making programmatic compromises

- Adjustment to research team values and culture

- Scrutiny by activist community

- Insecurities about scientific knowledge and language

- Accomodating pace of research, analysis and publication

Figure 3: Contributions and constraints in partnerships for rigorous, impact-oriented VAWG research. 


\section{Strengthening research and meeting growing demands for impact}

This paper has explored researcher-NGO/IO collaborations, highlighting potential benefits and challenges and raising questions, such as whether these types of partnerships might corrupt the research process or violate scientific boundaries. It is our contention that instead of 'rigging' results, if conducted with strong methods, integrity, and transparency, research collaborations to investigate complex social phenomena strengthen scientific rigour and offer promising models for the production of context-relevant, impact-oriented findings. Partnerships of this kind can also ensure that studies with society's most vulnerable populations will utilize designs that are attentive to their risks and result in findings that are used to make a difference.

Although this paper drew on examples from research on VAWG, there are many similar examples of research partnerships to address other complex problems of equity, human rights, and social justice (homelessness, child maltreatment, injecting drug use, sex work, disabilities to name a few). This complexity and the need for methodological rigor to tease out causation are among the numerous reasons that researcher-NGO/IO partnerships are well suited for such investigations. And, the most important advantage is: 'impact'.

Growing donor demands for impact come as quite good news for research teams working on rights-related issues and marginalized populations. From our history of collaborative projects, this has been the 'core business' of our work but is often underfunded. Partnerships increase the likelihood of producing credible data and seizing strategic opportunities to use this evidence.

\section{Conclusion}

Ultimately, whether we are using research to identify effective interventions for VAWG or to shift other forms of deeply embedded discrimination, we will have to seek answers to inherently social and political questions. These include: What causes women (or others) to be abused or marginalized in such large proportions? And, which structural forces must we shift to prevent these violations? In our politically, economically, and socially stratified world, the divisions that create extraordinary disadvantages for particular groups are likely to persist. To find realistic solutions, researchers and organizations working for the benefit of women and other potentially marginalised populations need to plan proactively and creatively to make the best use of research opportunities and disseminate meaningful findings to improve the rights and well-being of vulnerable people. 


\section{About the Authors}

Cathy Zimmerman, $\mathrm{PhD}$, is a social-behavioural scientist with the Gender Violence and Health Centre, Department of Global Health and Development at the London School of Hygiene and Tropical Medicine, United Kingdom.

Mazeda Hossain, $\mathrm{PhD}$, is a social epidemiologist with the Gender Violence and Health Centre, Department of Global Health and Development at the London School of Hygiene and Tropical Medicine, United Kingdom.

Email: Mazeda.Hossain@1shtm.ac.uk

Ligia Kiss, $\mathrm{PhD}$, is a social epidemiologist with the Gender Violence and Health Centre, Department of Global Health and Development at the London School of Hygiene and Tropical Medicine, United Kingdom.

Email: Ligia.Kiss@1shtm.ac.uk

Lori Michau is the co-founder and co-director for Raising Voices, Uganda.

Email: lori.michau@ raisingvoices.org

Rosilyne Borland is the Regional Specialist for South America at International Organization for Migration (IOM).

Email: rborland@iom.int

Charlotte Watts, $\mathrm{PhD}$, is a social epidemiologist with the Gender Violence and Health Centre, Department of Global Health and Development at the London School of Hygiene and Tropical Medicine, United Kingdom.

Email: Charlotte.Watts@1shtm.ac.uk 


\section{References}

${ }^{1}$ Bonell, C., Fletcher, A., Morton, M., Lorenc, T., \& Moore, L. (2012) Realist randomised controlled trials: A new approach to evaluating complex public health interventions. Social Science \& Medicine 75(12), 2299-2306.

${ }^{2}$ Kazi, M. (2003) Realist Evaluation for Practice. British Journal of Social Work 33(6): 803-818.

${ }^{3}$ Collins, H. M. and Evans, R. (2002) The Third Wave of Science Studies: Studies of Expertise and Experience. Social Studies of Science 32(2): 235-296.

${ }^{4}$ Ferguson, G. (2015) Working with academics: it gets easier. Honestly. The Guardian, 10 December.

${ }^{5}$ Shepperd, S., Lewin, S., Straus, S., Clarke, M., Eccles, M. P., Fitzpatrick, R., Wong, G., Sheikh, A. (2009) Can we systematically review studies that evaluate complex interventions? PLoS Medicine, 6(8) e1000086.

${ }^{6}$ Smith, S., Ward, V., and House, A. (2011) "Impact" in the proposals for the UK's Research Excellence Framework: Shifting the boundaries of academic autonomy. Research Policy 40(10): 1369-1379.

${ }^{7}$ Ptáčková, K. (2012) Professional curiosity engaged in policy sociology. Human Affairs 22(4): 475-491.

${ }^{8}$ Devries, K.M., Mak, J.Y.T., García-Moreno, C., Petzold, M., Child, J.C., Falder, G., Lim, S,. Bacchus, L.J., Engell, R. E., Rosenfeld, L., Pallitto, C., Vos, T., Abrahams, N., Watts, C.H. (2013) Global health. The global prevalence of intimate partner violence against women. Science 340(6140): 1527-1528.

${ }^{9}$ UN General Assembly (1993). Declaration on the Elimination of Violence against Women, 20 December 1993. In 85th Plenary Meeting A/RES/48/104.

${ }^{10}$ Michau, L., Horn, J., Bank, A., Dutt, M.,and Zimmerman, C. (2015) Prevention of violence against women and girls: lessons from practice. The Lancet 385(9978), 1672-1684

${ }^{11}$ Abramsky, T., Devries, K., Kiss, L., Nakuti, J., Kyegombe, N., Starmann, E., Cundill, B., Francisco, L., Kaye, D, Musuya, T., Michau, L., Watts, C. (2014) Findings from the SASA! Study: a cluster randomized controlled trial to assess the impact of a community mobilization intervention to prevent violence against women and reduce HIV risk in Kampala, Uganda. BMC Medicine 12(1): 122

${ }^{12}$ Craig, P., Dieppe, P., Macintyre, S., Michie, S., Nazareth, I., and Petticrew, M. (2008) Developing and Evaluating Complex Interventions: New Guidance. Medical Research Council, $U K$.

${ }^{13}$ Davies, H., Nutley, S., and Walter, I. (2005) Approaches to assessing the non-academic impact of social science research. St. Andrews, Scotland: Research Unit of Research (May): 1-35.

${ }^{14}$ Heise, L. (2014). What works to prevent partner violence. London School of Hygiene and Tropical Medicine. London. Is this posted on the web anywhere? http://strive.lshtm.ac.uk/resources/what-works-prevent-partner-violence-evidence-overview

${ }^{15}$ Kyegombe, N., Abramsky, T., Devries, K.M., Starmann, E., Michau, L., Nakuti, J., Musuya, T., Heise, L., Watts, C. (2014) The impact of SASA!, a community mobilization intervention, on reported HIV-related risk behaviours and relationship dynamics in Kampala, Uganda. Journal of the International AIDS Society 17 (Nov): 19232 
${ }^{16}$ Hossain, M., Zimmerman, C., Kiss, L., Abramsky, T., Kone, D., Bakayoko-Topolska, M, Watts, C. (2014) Working with men to prevent intimate partner violence in a conflict-affected setting: a pilot cluster randomized controlled trial in rural Côte d'Ivoire. BMC Public Health 14: 339.

${ }^{17}$ Zimmerman, C., Kiss, L., and Hossain, M. (2011) Migration and Health: A Framework for 21st Century Policy-Making. PLoS Med 8(5). http://dx.doi.org/10.1371/journal.pmed.1001034

${ }^{18}$ Zimmerman C, Watts C, Hossain M, (2011) Human trafficking and health: Conceptual frameworks to inform policy, intervention and research. Social Science \& Medicine. 73(2):32735 .

${ }^{19}$ Zimmerman, C., Stöckl, H. Understanding and Addressing Violence Against Women. Human Trafficking. World Health Organization (WHO), Pan American Health Organization (PAHO) (2012). Geneva. http://apps.who.int/iris/bitstream/10665/77394/1/WHO_RHR_12.42_eng.pdf

${ }^{20}$ Zimmerman, C. and Watts, C. (2003) WHO ethical and safety recommendations for interviewing trafficked women. World Health Organization. Geneva WHO.

${ }^{21}$ Ellsberg, M., \& Heise, L. (1999). Putting women's safety first: ethical and safety recommendations for research on domestic violence against women. World Health Organization (WHO). Geneva.

${ }^{22}$ Ellsberg M., Heise L., Peña R., Agurto S., Winkvist A. (2003) Researching Domestic Violence Against Women: Methodological and Ethical Considerations. Studies in Family Planning 32(1): 1-6.

${ }^{23}$ Cashman, S. B., Adeky, S., Allen, A. J., Corburn, J., Israel, B. A, Montaño, J., Rafelito, A., Rhodes, S.D., Swanston, S., Wallerstein, N., Eng, E. (2008). The power and the promise: working with communities to analyze data, interpret findings, and get to outcomes. American Journal of Public Health 98(8): 1407-17.

${ }^{24}$ Davies C. and Ward H. (2011) Safeguarding Children across Services. Messages from Research. Jessica Kingsley Publishers. London and Philadelphia

${ }^{25}$ García-Moreno, C., Zimmerman, C., Morris-Gehring, A., Heise, L., Amin, A., Abrahams, N., Montoya, O., Bhate-Deosthali, P., Kilonzo, N., Watts, C. (2014) Addressing violence against women: a call to action. The Lancet 385(9978): 1685-1695. 